\title{
Design of Optimization-based Controllers Applied to an Ethanol Steam Reformer for Hydrogen Production
}

\author{
D. Recio-Garrido ${ }^{\dagger *}$, C. Ocampo-Martinez ${ }^{\dagger, \hbar}$, M. Serra-Prat ${ }^{\dagger, \hbar}$ \\ $\dagger$ Institut de Robòtica i Informàtica Industrial (CSIC-UPC) \\ Llorens i Artigas, 4-6, 2nd floor, 08028 Barcelona, Spain \\ ${ }^{*}$ Automatic Control Department (ESAII), Technical University of Catalonia \\ Pau Gargallo, 5, 08028 Barcelona, Spain
}

\begin{abstract}
This paper focuses on the control of a low-temperature ethanol steam reformer for in-situ hydrogen production. For this purpose, three optimization-based control configurations are proposed, namely, a linear model-based predictive controller, a linear quadratic regulator with output error integral action and a cascade control combining the two previous configurations. In all cases, control objectives aim at obtaining the desired flow of hydrogen while keeping the carbon monoxide at its nominal working point under input and output operational constraints. Output tracking and robustness of each configuration are compared using two key performance indicators that evaluate the output errors and the smoothness of the control signals. Simulation results allow to compare the characteristics of each control configuration when applied to the non-linear model of the ethanol steam reformer.
\end{abstract}

Keywords: Ethanol steam reformer, model predictive control, linear quadratic regulator, cascade control, multi-objective optimization

\section{Introduction}

Hydrogen can store and deliver usable energy. Nowadays, it is considered a promising energy vector for both stationary and mobile applications. Likewise, hydrogen presents costly distribution and storage which makes in-situ hydrogen production techniques to become more interesting.

Steam reforming is a current option for in situ hydrogen production. It consists of an endothermic process that requires an external heat source and produces a gas stream composed primarily of hydrogen $\left(\mathrm{H}_{2}\right)$, carbon monoxide $(\mathrm{CO})$ and carbon dioxide $\left(\mathrm{CO}_{2}\right)$. Among the different reforming techniques, steam reforming is the one that presents the lowest operating temperature (about $800 \mathrm{~K}$ ) and produces the reformate with the highest $\mathrm{H}_{2} / \mathrm{CO}$. Conversely, it does have the highest $\mathrm{CO}$ emissions [1].

Among the different fuels for hydrogen production by steam reforming, ethanol is the one that has got more interest in the last decade. Basically, ethanol is renewable as it can be extracted from corn and sugar cane; it is easy to transport, biodegradable and low in toxicity; it can be easily decomposed in the presence of water to generate a hydrogen-rich mixture and it is free from catalysts poison such as sulfur [2].

Since steam reforming is a catalytic process, selection of catalysts is a fundamental aspect that affects the performance of the reformer. Improvements in the field of the ethanol steam reformers (ESR) have been achieved with the development of

\footnotetext{
*Corresponding author. Tel: +34 93401 5752; Fax: +34 934015750.

Email address: drecio@iri.upc .edu (D. Recio-Garrido ${ }^{\dagger}$ )
}

cobalt-based catalysts, which allow reforming ethanol at low temperatures (about $673 \mathrm{~K}$ ) [3]. While cobalt-based catalysts present important practical advantages in terms of energy consumption, two major concerns appear when reducing the temperature, namely, fast catalyst deactivation by coking and hydrogen consuming by-products formation by methanation. First and second stages of the reforming process solve those problems by an ethanol dehydrogenation followed by an acetaldehyde reforming [4]. The reforming process is completed with a third stage that reduces $\mathrm{CO}$ content by means of a water gas shift reaction. The kinetic expressions for the reactions taking place in first to second stages and third stage are taken from [4] and [5], respectively.

In the meanwhile, the modeling of the chemical system is still an open research subject. The work presented in [6] derives a complex simulation-oriented model of the ESR while [4] shows how to obtain a model oriented for control purposes. Both works share the fact that the catalytic packed bed reactor can be modeled using the same dynamic equations as those used for modeling a plug-flow reactor, found in [7].

In this paper simulations are based on a non-linear model that corresponds to a one-dimensional, pseudo-homogeneous, nonsteady-state model based on mass balances [8]. The non-linear model is improved from the model presented in [8] by considering the volumetric flow rate of the gases inside the reactor as a function of time and location along the reactor. A linear controloriented model, obtained after linearization, model-order reduction and temporal discretization of the non-linear model, is used to design the linear controllers. 
Literature concerning the design of controllers for ESR is limited. In [8] the authors perform a controllability analysis on the ESR in order to determine the best input-output pairing for PIDs controllers while [9] performs this controllability analysis in terms of the global plant with plantwide global efficiency objectives. Although control structures are given in both cases, any controllers are designed for the closed-loop.

The multivariable control configurations proposed in this paper must handle the high non-linearities present in those chemical systems and should be able to satisfy the desired references in hydrogen production while keeping the carbon monoxide at its nominal working point.

The two control techniques used in this paper, linear modelbased predictive control (LMPC) [10] and linear quadratic regulator with output integral action (LQRi) [11], minimize a multiobjective function. Several advantages make both control techniques suitable for the ESR application: they can deal with MIMO, non-minimum phase, inverse response, large-scale systems and allow multi-objective optimization. Furthermore, the LMPC can introduce operational constraints into the control problem naturally.

The main contribution of this paper is to present and compare optimization-based control strategies that can tackle with the non-linear behaviour of the ESR showing an alternative to the classical control configurations based on decentralized PIDs.

The paper is structured as follows: Section 2 gives a chemical description of the ESR. Section 3 details the basic mathematical equations modeling the dynamics of the system and the assumptions used to simplify the model. Furthermore, the non-linear model used for simulations and the linear controloriented model used for the design of the controllers are presented. Section 4 presents the control specifications and the performance indicators used for the analysis of the performance of the control configurations. Section 5 shows the characteristics and the schemes for each control configuration. Section 6 exposes and compares the simulation results in two different scenarios: first, output tracking and second, rejection of additive load disturbances. Finally, Section 7 gathers the conclusions of the work and gives some further work lines.

\section{System Description}

This paper considers an isothermal low-temperature ESR for the production of hydrogen. Cobalt-based catalysts allow the steam reforming of ethanol to take place at low temperatures (613-673K) [3]. However, a direct transformation from ethanol to hydrogen using these catalysts presents two major drawbacks, namely, methanation and oxidizing atmosphere. The former favors a costly side reaction that produces methane by consuming hydrogen, and the latter restricts the creation of metallic cobalt necessary for the reforming process.

The reforming process is split into three independent stages [4]. In order to create a reducing atmosphere, in the first stage ethanol $\left(\mathrm{C}_{2} \mathrm{H}_{5} \mathrm{OH}\right)$ dehydrogenates into acetaldehyde $\left(\mathrm{C}_{2} \mathrm{H}_{4} \mathrm{O}\right)$ and hydrogen $\left(\mathrm{H}_{2}\right)$ over a tin dioxide catalyst $\left(\mathrm{SnO}_{2}\right)$ at $648 \mathrm{~K}$,

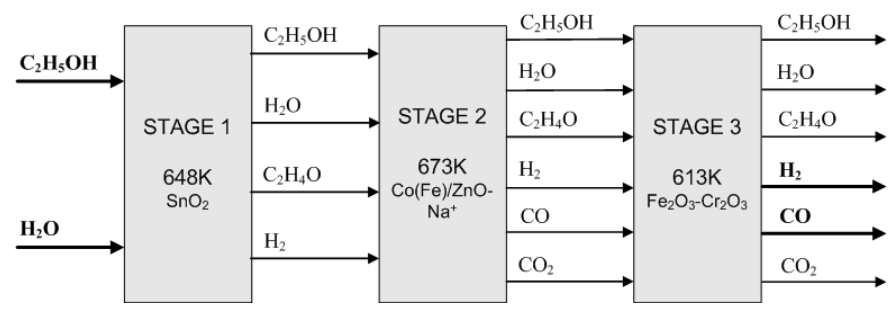

Figure 1: Scheme of the ethanol reformer unit.

i.e.,

$$
\mathrm{C}_{2} \mathrm{H}_{5} \mathrm{OH} \underset{648 \mathrm{~K}}{\stackrel{\mathrm{SnO}_{2}}{\longrightarrow}} \mathrm{C}_{2} \mathrm{H}_{4} \mathrm{O}+\mathrm{H}_{2} \text {, }
$$

and in the second stage, acetaldehyde is reformed under presence of water $\left(\mathrm{H}_{2} \mathrm{O}\right)$ into hydrogen and carbon monoxide $(\mathrm{CO})$ and carbon dioxide $\left(\mathrm{CO}_{2}\right)$ over a zinc oxide-supported cobalt with iron addition catalyst $(\mathrm{Co}(\mathrm{Fe}) / \mathrm{ZnO})$ at $673 \mathrm{~K}$, i.e.,

$$
\begin{aligned}
\mathrm{C}_{2} \mathrm{H}_{4} \mathrm{O}+\mathrm{H}_{2} \mathrm{O} & \stackrel{\mathrm{Co}(\mathrm{Fe}) / \mathrm{ZnO} \mathrm{Na}^{+}}{673 \mathrm{~K}} 2 \mathrm{CO}+3 \mathrm{H}_{2}, \\
\mathrm{C}_{2} \mathrm{H}_{4} \mathrm{O}+3 \mathrm{H}_{2} \mathrm{O} & \stackrel{\mathrm{Co}(\mathrm{Fe}) / \mathrm{ZnO} \mathrm{Na}^{+}}{\underset{673 \mathrm{~K}}{\longrightarrow}} 2 \mathrm{CO}_{2}+5 \mathrm{H}_{2}, \\
\mathrm{CO}+\mathrm{H}_{2} \mathrm{O} & \stackrel{\mathrm{Co}(\mathrm{Fe}) / \mathrm{ZnO} \mathrm{Na}^{+}}{673 \mathrm{~K}} \mathrm{CO}_{2}+\mathrm{H}_{2} .
\end{aligned}
$$

Reactions (2a) and (2b) take place in parallel while reaction (2c) occurs in series with reaction (2a). In order to reduce the methane formation and coking on the second stage, iron and sodium are added to the $\mathrm{Co} / \mathrm{ZnO}$ catalyst [12].

Finally, the $\mathrm{CO}$ content is reduced in a third stage by means of a water gas shift reaction. The $\mathrm{CO}$ reacts under presence of water over an iron trioxide/chromium trioxide catalyst $\left(\mathrm{Fe}_{2} \mathrm{O}_{3}\right.$ $\mathrm{Cr}_{2} \mathrm{O}_{3}$ ) producing $\mathrm{CO}_{2}$ and $\mathrm{H}_{2}$, i.e.,

$$
\mathrm{CO}+\mathrm{H}_{2} \mathrm{O} \stackrel{\mathrm{Fe}_{2} \mathrm{O}_{3}-\mathrm{Cr}_{2} \mathrm{O}_{3}}{\underset{613 \mathrm{~K}}{\longrightarrow}} \mathrm{CO}_{2}+\mathrm{H}_{2} .
$$

Each one of the three stages corresponds to a monolithic reactor. Figure 1 shows the reformer unit with the three monolithic reactors in series. Inputs correspond to ethanol and water and outputs correspond to ethanol, water, acetaldehyde, hydrogen, carbon monoxide and carbon dioxide.

For control purposes, ethanol and water act as the manipulated variables and hydrogen and carbon monoxide are the measured and controlled output variables.

\section{Mathematical Modeling}

An accurate knowledge of the dynamic response of the reactor results essential towards the design of model-based controllers for the whole reformer. This section presents the nonlinear model (NLsys) used for simulation as well as the linear control-oriented model (LRDsys) used for the controllers design.

\subsection{Non-linear Simulation Model}

A one-dimensional, pseudo-homogeneous, dynamic model has been used to represent the ethanol reforming process in the 
already referenced series of monolithic reactors (Figure 1). The major assumptions underlying the model are the following:

- Isothermal operation within each stage is considered.

- Plug-flow reactor modeling is assumed since the flow inside the channels is laminar.

- Diffusion action is assumed to be slower than the convection action and therefore, terms related to diffusion are neglected.

- The use of low-diameter monoliths supports the assumption of 1-D model avoiding the occurrence of pronounced radial mass profiles.

- Isobaric conditions are assumed due to the high void fraction of the monolithic structures $(\xi=0.66)$. Thus, the pressure inside the reformer is $101,325 \mathrm{~Pa}$.

- Gas properties are function of temperature and gas concentration. Ideal gas law is applicable due to low operating pressure.

As it is found in [4], the mass balance equation together with the initial and boundary conditions can be expressed, after considering all the assumptions, as

$$
\begin{aligned}
& \frac{\partial C_{j}}{\partial t}+\frac{\partial\left(C_{j} v\right)}{\partial z}=v_{j, i} r_{i}, \\
& C_{j}(0, z)=C_{j, 0}(z), \\
& C_{j}(t, 0)=C_{j, i n}(t),
\end{aligned}
$$$$
\forall z \in[i n, L],
$$$$
\forall t>0 \text {, }
$$

where $j$ is the component number $j=1, \ldots, 6\left(\mathrm{C}_{2} \mathrm{H}_{5} \mathrm{OH}, \mathrm{H}_{2} \mathrm{O}\right.$, $\mathrm{C}_{2} \mathrm{H}_{4} \mathrm{O}, \mathrm{H}_{2}, \mathrm{CO}, \mathrm{CO}_{2}$, respectively), $i$ is the reaction number $i=1, \ldots, 3$ (reactions (1) to (3), respectively), $C$ is the concentration given in $\mathrm{mol} \mathrm{m}^{-3}, r$ is the reaction rate given in mol m${ }^{-3} \mathrm{~s}^{-1}, v$ is the linear velocity of the gases given in $\mathrm{m} \mathrm{s}^{-1}$, $t$ is the time given in s, 0 denotes the initial time, in denotes the reactor inlet and $L$ denotes the reactor outlet. Refer to the Appendix A for the kinetic expressions.

In the simplified mass balance expression presented in (4a), $v$ should also be expressed in function of $C_{j}$ in order to be able to solve the set of PDEs. This work improves the model reported in [4] considering that $v$ varies not only with time but also with the position along the reactor's axial direction $z$. According to [13], in a plug-flow reactor under isothermal and isobaric conditions, $v$ can be expressed as

$$
\begin{gathered}
v=v_{i n}(1+\varepsilon X), \\
X=\frac{\varepsilon\left(C_{j, i n}-C_{j}\right)}{C_{j}-C_{j, i n}},
\end{gathered}
$$

where $X$ is the conversion given in $\%$ and $\varepsilon$ is the adimensional reagents-products molar relation for the considered reaction. However, in the sequel, the velocity of gases in the reactor will be called volumetric flow rate which is expressed as $Q=A v$, being $A$ the section of the tubular reactor given in $\mathrm{m}^{2}$. Also the term molar flow rate, denoted as $F$, which is related with the

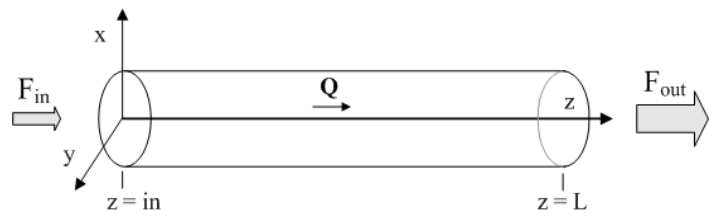

Figure 2: Schematic representation of the ESR.

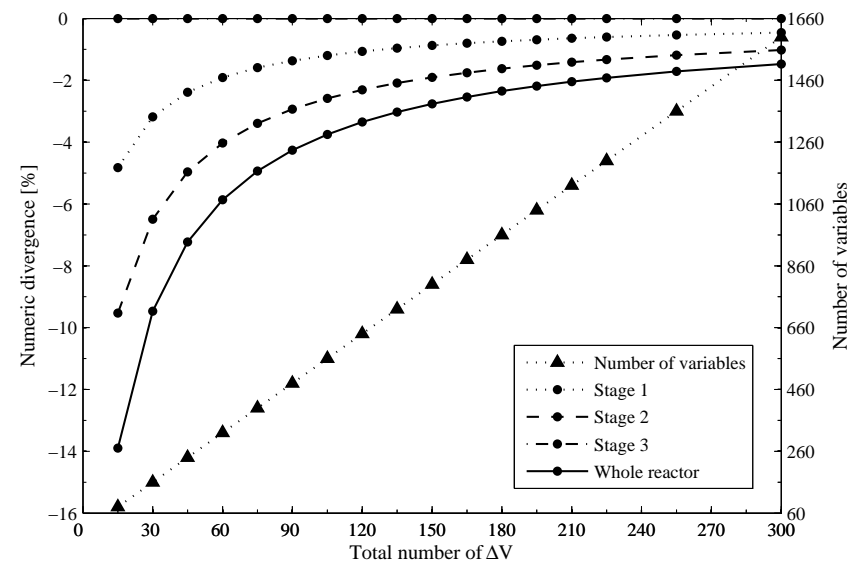

Figure 3: Numerical divergence in conservation of mass in function of the total number of discretization volumes $\Delta \mathrm{V}$ along $z$.

concentrations as $F_{j}=Q C_{j}$ is used. Both $Q$ and $F$ are given in $\mathrm{m}^{3} \mathrm{~s}^{-1}$ and $\mathrm{mol} \mathrm{s}^{-1}$, respectively. Figure 2 shows the schematic representation of each one of the three monolithic reactors.

\subsubsection{Spatial Discretization}

The set of mass balance equations presented in (4) to (6) represents the spatial derivatives of the concentrations with respect to time and space. This space dependence is discretized using backward finite differences,

$$
\frac{\partial C_{j}}{\partial z}=\frac{C_{j}(z)-C_{i}(z-1)}{\Delta z},
$$

resulting in a model where the concentrations vary with time and are considered as constants within each differential volume ( $\Delta V=A \Delta z$ ). Spatial discretization results in a lumped parameter system and allows the use of lumped systems theory. However, it carries a numerical divergence in the conservation of mass that increases when decreasing the number of differential volumes along the reactor.

Figure 3 shows the loss of mass in percentage between the input and the output in function of the total number of $\Delta V$ along $z$. A mass balance for each one of the three stages independently is shown as well as the global mass balance for the whole reactor. Moreover, it is shown the number of variables that need to be solved in function of the number of discretization points considered.

Notice from Figure 3 that the divergence only happens on stages 1 and 2, where $Q$ presents a variable profile with $z$. This divergence happens since the volumetric flow rate is assumed to be constant within each differential volume but changes 
abruptly from one volume to another. With the increment of $\Delta \mathrm{V}$, this difference in the volumetric flow rate between neighbor volumes decreases and consequently, the loss of mass decreases. Stage 3 presents a constant $Q$, i.e. the reaction implies the same number of moles in reagents and products, and the numerical divergences are zero.

In this paper, simulations have been carried out considering $45 \Delta \mathrm{V}$ which represents 240 variables (concentrations). In this case, the mass divergence considering all the stages corresponds to $-7.23 \%$. Due to the high computational burden when solving the set of DAEs, and therefore, from a practical point of view, this divergence is accepted.

\subsubsection{Behavioral Analysis}

Characteristics of the NLsys model can be obtained from static and dynamic tests in open loop. Static analysis considers static profiles of each variable with respect to the position in $z$ direction while dynamic analysis examines the behavior of the output variables after step changes around the nominal values in the input variables.

Figure 4 shows the static profiles for the molar flow rates and the concentrations of all the species present in the reactor, as well as the profiles of the volumetric flow rate and temperature. Note that $T$ remains constant within each stage at its optimal working value, i.e., $T_{1}=648 \mathrm{~K}, T_{2}=673 \mathrm{~K}$, and $T_{3}=613 \mathrm{~K}$ [4]. In the transitions between stages, coexistence of two temperatures is assumed since no energy balances are considered. This assumption affects all the other variables, showing abrupt changes in their values at the transition between stages. $Q$ increases in the first and second stages along $z$ because there are more moles of product than moles of reagents $\left(\varepsilon_{1}, \varepsilon_{2}>0\right)$. However, in the third stage the reaction produces the same number of moles and $\varepsilon_{3}=0$. Concerning $F$ and $C$ profiles, inert gases in stages 1 and $2\left(\mathrm{H}_{2} \mathrm{O}\right.$ and $\mathrm{C}_{2} \mathrm{H}_{5} \mathrm{OH}$, respectively) show a constant $F$ profile while its $C$ profile changes. This is the result of keeping the product $F_{j}=Q C_{j}$ constant within each stage. In stage $3, Q$ remains constant, and hence, inert gases $\left(\mathrm{C}_{2} \mathrm{H}_{5} \mathrm{OH}\right.$ and $\left.\mathrm{C}_{2} \mathrm{H}_{4} \mathrm{O}\right)$ present constant profiles both in $F$ and C.

Figure 5 shows the evolution in time of all the $F_{j}$ outputs for step changes of $\pm 20 \%$ on $\mathrm{F}_{\mathrm{C}_{2} \mathrm{H}_{5} \mathrm{OH} \text {,in }}$, and $\mathrm{F}_{\mathrm{H}_{2} \mathrm{O} \text {, in }}$ inputs (left and right columns, respectively). Analyzing the output responses, the following effects should be noticed:

- a sudden change in all the outputs when the steps are applied, which is a consequence of the constant pressure assumption inside the reformer,

- in some outputs, after the instant response, a combination of a non-minimum phase and very slow dynamics behavior of about $9 \mathrm{~s}$, and

- an inverse response in $F_{\mathrm{H}_{2} \mathrm{O}, \mathrm{L}}$ for steps in $F_{\mathrm{C}_{2} \mathrm{H}_{5} \mathrm{OH} \text {,in }}$ and in $F_{\mathrm{H}_{2}, L}, F_{\mathrm{CO}, L}$ and $\mathrm{F}_{\mathrm{CO}_{2}, L}$ for steps in $F_{\mathrm{H}_{2} \mathrm{O}, \mathrm{in}}$.

\subsection{Control-oriented Model}

The first step to obtain the model used for the design of the linear controllers is to linearize the NLsys model. Thus, a linear

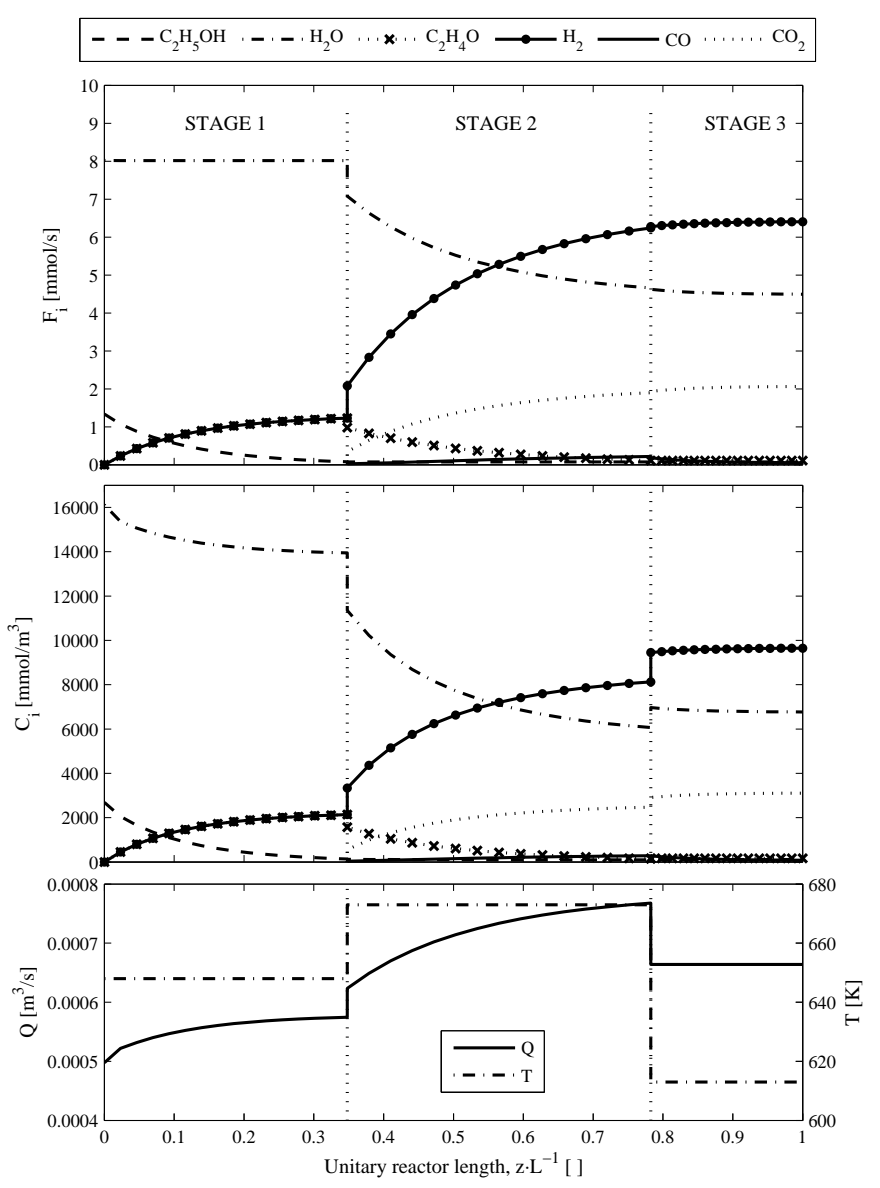

Figure 4: Molar flow rate profiles (top), concentration profiles (middle) and volumetric flow rate and temperature profiles (bottom) in function of the position along the reactor length at steady state.

model (Lsys) of 240 states is obtained. In this model, states have a physical meaning and represent the $C_{j}$ within each $\Delta V$.

Unfortunately, the Lsys model is not fully-state observable, which is required for control purposes since only outputs can be measured. Therefore, the second step consists in a model-order reduction based on a Hankel-norm approximation of the Lsys model. All the dynamic information of the system is concentrated in less than 15 states. Only the first 12 states are kept for practical purposes, obtaining a 12-states fully-state observable model, named LRsys. A drawback resulting from the model reduction procedure is the loss of the physical sense of the state variables. However, for control purposes this physical meaning feature is not necessarily relevant since the most important features are related to the trade off between accuracy, simplicity and compactness.

Finally, the last step consists in a temporal discretization of the LRsys model since all the configurations proposed in this paper are in discrete time. Time discretization is made assuming piecewise constant control inputs over the sampling time (zero-order hold method). The sampling time is chosen to be $T_{s}=0.3 \mathrm{~s}$, which is ten times faster than the fastest time constant of the NLsys.

The LRDsys model used for the design of the linear con- 

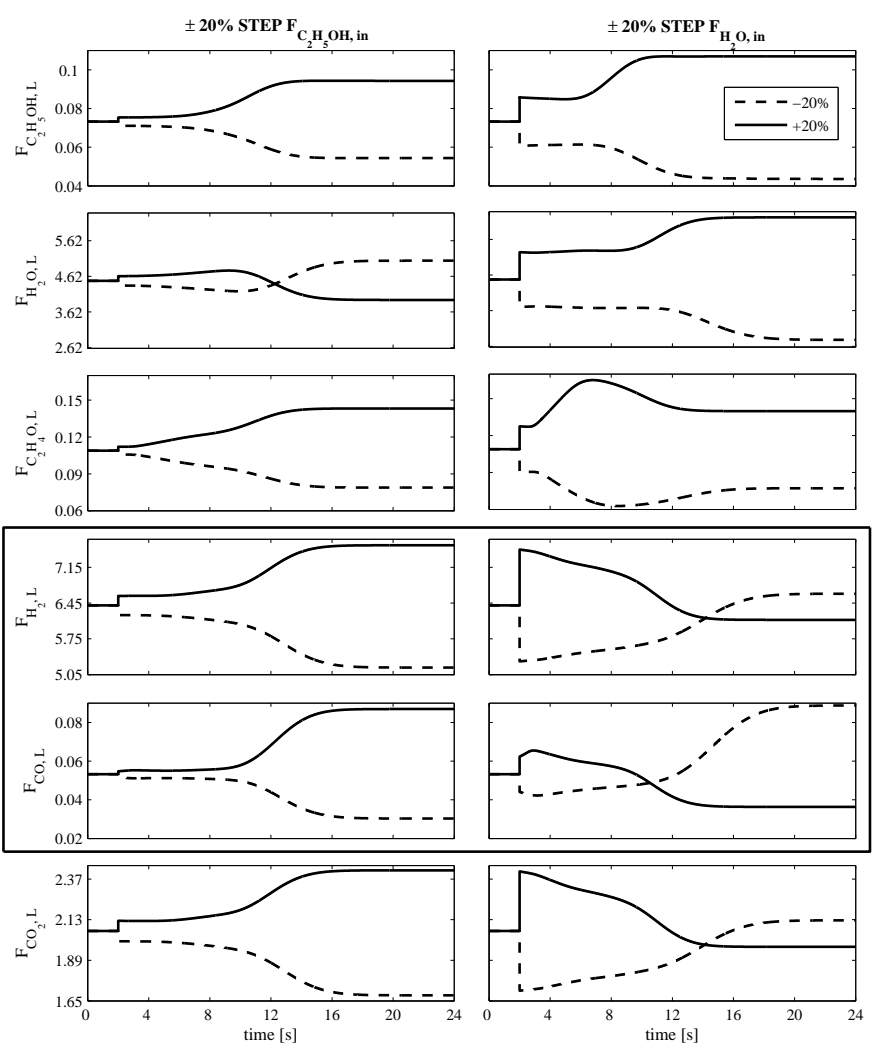

Figure 5: Molar flow rates of all the components at the output of the ESR for steps of $\pm 20 \%$ around the steady state of the ethanol input (left column) and water input (right column) in function of time.

trollers can be expressed in state-space representation as

$$
\begin{aligned}
x_{r}(k+1) & =A_{r d} x_{r}(k)+B_{r d} u(k), \\
y(k) & =C_{r d} x_{r}(k)+D_{r d} u(k),
\end{aligned}
$$

where $x_{r}(k) \in \mathbb{R}^{12}$ is the vector of the state variables and $A_{r d} \in \mathbb{R}^{12 \times 12}, B_{r d} \in \mathbb{R}^{12 \times 2}, C_{r d} \in \mathbb{R}^{2 \times 12}$ and $D_{r d} \in \mathbb{R}^{2 \times 2}$ are the matrices for the LRDsys model. Input and output vectors are, respectively, $u(k) \in \mathbb{R}^{2}$ and $y(k) \in \mathbb{R}^{2}$.

The direct input-output feed-through represented by matrix $D_{r d}$ results from the assumption that pressure must be constant inside the reformer, i.e., at the time one molecule of gas enters the reactor, another molecule must leave it.

Nominal working values correspond to the steady state values given in Table 1 where $\eta^{\mathrm{H}_{2}}$ is the $\mathrm{H}_{2}$ yield, $X_{\mathrm{C}_{2} \mathrm{H}_{5} \mathrm{OH}}$ is the $\mathrm{C}_{2} \mathrm{H}_{5} \mathrm{OH}$ conversion, $X_{\mathrm{C}_{2} \mathrm{H}_{4} \mathrm{O}}$ is the $\mathrm{C}_{2} \mathrm{H}_{4} \mathrm{O}$ conversion and $\gamma_{C O}$ is the $\mathrm{CO}$ molar fraction. All those values are calculated as defined in [8].

Validation of the LRDsys model against the NLsys model for steps of $\pm 20 \%$ in both inputs around the nominal working point is shown in Figure 6. It can be noted that $\mathrm{H}_{2}$ steady-state absolute errors are in the range $[0.27 \%, 0.53 \%]$, which can be considered as negligible. On the contrary, $\mathrm{CO}$ steady-state absolute errors are in the range [6.90\%, 16.90\%], which must be translated into keeping the $\mathrm{CO}$ at its nominal working point in the control specifications.
Table 1: Steady state values for the ESR.

\begin{tabular}{lllc}
\hline Variable & $\begin{array}{c}\text { Nominal point } \\
{[\mathrm{mmol} / \mathrm{s}]}\end{array}$ & Variable & $\begin{array}{c}\text { Nominal point } \\
{[\%]}\end{array}$ \\
\hline $\mathrm{F}_{\mathrm{C}_{2} \mathrm{H}_{5} \mathrm{OH}, \text { in }}$ & 1.34 & $\eta^{H_{2}}$ & 80.85 \\
$\mathrm{~F}_{\mathrm{H}_{2} \mathrm{O}, \text { in }}$ & 8.21 & $X_{\mathrm{C}_{2} \mathrm{H}_{5} \mathrm{OH}}$ & 92.53 \\
$\mathrm{~F}_{\mathrm{H}_{2}, \mathrm{~L}}$ & 6.50 & $X_{\mathrm{C}_{2} \mathrm{H}_{4} \mathrm{O}}$ & 82.33 \\
$\mathrm{~F}_{\mathrm{CO}, \mathrm{L}}$ & 0.18 & $\gamma_{\mathrm{CO}, \mathrm{L}}$ & 0.47 \\
\hline
\end{tabular}
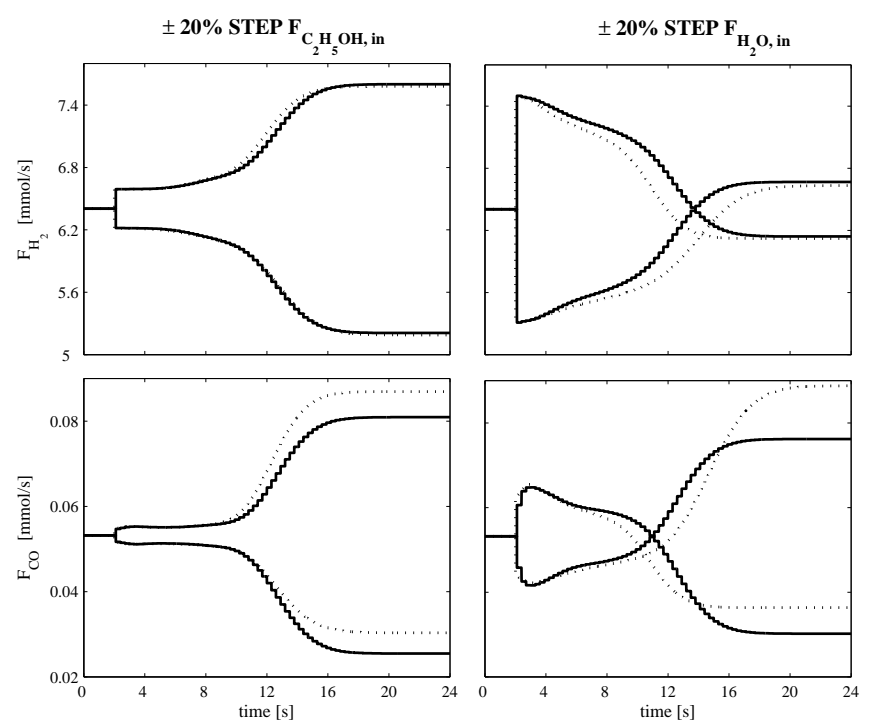

Figure 6: Validation of the LRDsys model with the NLsys model.

\section{Control Specifications and Performance Indicators}

Usually the application of the hydrogen produced by the ESR determines de control specifications to consider. Since this fact has not been taken into account in this paper, the control specifications have been chosen as a function of the accuracy of the LRDsys to represent the NLsys model.

Thus, the control objectives are chosen to track the $\mathrm{H}_{2}$ output set point while keeping the $\mathrm{CO}$ output at its nominal working point. The reason is that the final purpose of an ESR is to supply the $\mathrm{H}_{2}$ demand no matter the considered application. Referring to the $\mathrm{CO}$ output, the accuracy of the LRDsys model decreases when being far from the nominal working value which limits the performance of the controllers to keep this output at its nominal working value. Besides, those two control objectives should simultaneously satisfy certain operational constraints and reject additive load disturbances. Note that model (7) only considers the water and ethanol inflows as exogenous manipulated inputs. Disturbances, when considered, act as additive signals affecting the inflows.

Table 2 summarizes the control specifications considered in this paper. The role of each variable indicates whether the variable is a manipulated input (MI) or a controlled measured output (CMO). Set point values, constraints and load disturbances are expressed as a percentage variation around the nominal 
Table 2: Control specifications for the ESR.

\begin{tabular}{lllccc}
\hline Variable & Role & Symbol & $\begin{array}{c}\text { Set } \\
\text { points }\end{array}$ & $\begin{array}{c}\text { Cons- } \\
\text { traints }\end{array}$ & $\begin{array}{c}\text { Distur- } \\
\text { bances }\end{array}$ \\
\hline $\mathrm{F}_{\mathrm{C}_{2} \mathrm{H}_{5} \mathrm{OH} \text {, in }}$ & $\mathrm{MI}$ & $\mathrm{u}_{\mathrm{C}_{2} \mathrm{H}_{5} \mathrm{OH}}$ & - & $\pm 20 \%$ & $\pm 10 \%$ \\
$\mathrm{~F}_{\mathrm{H}_{2} \mathrm{O}, \text { in }}$ & $\mathrm{MI}$ & $\mathrm{u}_{\mathrm{H}_{2} \mathrm{O}}$ & - & $\pm 20 \%$ & $\pm 10 \%$ \\
$\mathrm{~F}_{\mathrm{H}_{2}, \mathrm{~L}}$ & $\mathrm{CMO}$ & $\mathrm{y}_{\mathrm{H}_{2}}$ & $\pm 10 \%$ & $\pm 20 \%$ & - \\
$\mathrm{F}_{\mathrm{CO}, \mathrm{L}}$ & $\mathrm{CMO}$ & $\mathrm{y}_{\mathrm{CO}}$ & 0 & $\pm 20 \%$ & - \\
\hline
\end{tabular}

value. Constraints on the MI and CMO fixed at a maximum variation of $\pm 20 \%$ are imposed.

In addition to the specifications shown in Table 2, the control configuration should keep the output steady state errors as close to zero as possible. The trade off between fast $\mathrm{H}_{2}$ response and overshoots both in $\mathrm{H}_{2}$ and $\mathrm{CO}$ outputs is not specified. When using LMPC, the optimization time should allow real-time applications, i.e., it should be at most half the sampling time of the controller.

The performance of the different controllers is evaluated with two key performance indicators (KPI). The output indicator, namely $K P I_{y_{c}}$, represents the mean-square error between the outputs and their references. The smoothness indicator, namely $K P I_{\Delta u_{g}}$, is related to the smoothness of control movements. They are defined as

$$
\begin{aligned}
K P I_{y_{c}} & =\sqrt{\frac{1}{N} \sum_{k=1}^{N}\left[\frac{y_{r, c}(k)-y_{c}(k)}{y_{r, c}(k)}\right]^{2}}, \\
K P I_{\Delta u_{g}} & =\sqrt{\frac{1}{N} \sum_{k=1}^{N}\left[\frac{\Delta u_{g}(k)}{u(N)}\right]^{2}},
\end{aligned}
$$

where $N$ denotes the total number of samples, $y_{r, c}(k)$ is the output set point for the output component $c$ at time $k, y_{c}(k)$ is the measured output at time $k$ with $c \in\left\{H_{2}, C O\right\}, \Delta u_{g}$ is the incremental control movement applied at time $\mathrm{k}$ with $g \in\left\{\mathrm{C}_{2} \mathrm{H}_{5} \mathrm{OH}, \mathrm{H}_{2} \mathrm{O}\right\}$ and $u(N)$ corresponds to the last control signal within the simulation horizon.

\section{Closed-Loop Configurations}

The four closed-loop configurations compared in this paper correspond to decentralized PID, LMPC, LQRi and cascade LMPC-LQRi. As explained in Section 3, the NLsys model is used for simulation of the ESR and the LRDsys model is used for the design of the linear controllers.

\subsection{Decentralized PID}

In this configuration two different closed loops controlled by two independent PIDs are considered, one for the pair $\mathrm{C}_{2} \mathrm{H}_{5} \mathrm{OH}-\mathrm{H}_{2}$ and another one for the pair $\mathrm{H}_{2} \mathrm{O}-\mathrm{CO}$. This input-output pairing has been proved, in previous works, to be the best pairing when comparing different input-output controllability indexes, such as the relative gain array, the condition number and the Morari resiliency index [8].

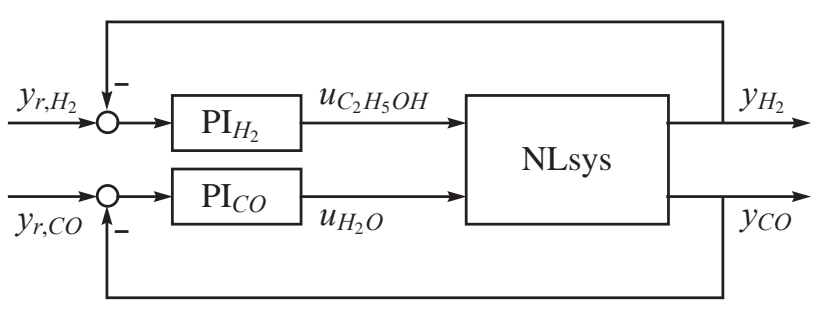

Figure 7: PID decentralized closed loop scheme.

Table 3: PIDs tuning parameters

\begin{tabular}{lrr}
\hline Controller & $k_{p} \cdot 10^{-3}$ & \multicolumn{1}{c}{$k_{i}$} \\
\hline $\mathrm{PI}_{H_{2}}$ & 5.0765 & 0.3641 \\
$\mathrm{PI}_{C O}$ & -7.4378 & 285.9578 \\
\hline
\end{tabular}

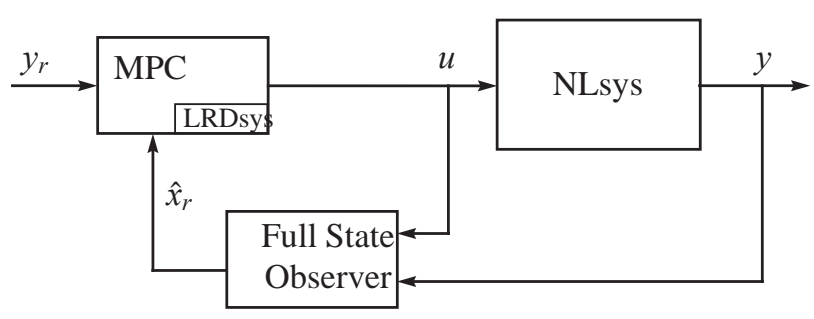

Figure 8: LMPC closed-loop scheme.

The decentralized PID control configuration is shown in Figure 7. The structure of the controllers correspond to the ideal PID form with a first order derivative filter,

$$
G(s)=k_{p}\left(1+\frac{k_{i}}{s}+\frac{k_{d} s}{T_{f} s+1}\right),
$$

where $G(s)$ is the transfer function of the PID controller, $k_{p}$ is the proportional gain, $k_{i}$ is the integral gain, $k_{d}$ the derivative gain and $T_{f}$ is the filter time constant.

The tuning procedure was made by means of the interactive PID tuning toolbox Simulink ${ }^{\circledR}$ Control Design ${ }^{\mathrm{TM}}$. The PID parameters in (8) for each control loop are shown in Table 3. The derivative gain is considered to be $k_{d}=0$ in all the cases, what actually corresponds to a PI controller.

\section{2. $L M P C$}

This configuration faces the control of the MIMO plant using a centralized LMPC with output feedback. Figure 8 shows the block diagram for this configuration. The MPC problem formulation presented in [10] and adapted to the ESR can be written as

$$
\min _{\Delta u} \sum_{p=0}^{H_{p}-1}\left\|y(k+p \mid k)-y_{r, c}(0 \mid k)\right\|_{w_{y}}^{2}+\|\Delta u(k+p \mid k)\|_{w_{r}}^{2},
$$


Table 4: LMPC tuning parameters

\begin{tabular}{|c|c|c|c|c|c|c|}
\hline \multirow[b]{2}{*}{ Time instant } & \multicolumn{4}{|c|}{ Weights } & \multicolumn{2}{|c|}{ Constraints } \\
\hline & $q_{H_{2}}$ & $q_{C O}$ & $r_{\mathrm{C}_{2} \mathrm{H}_{5} \mathrm{OH}}$ & $r_{\mathrm{H}_{2} \mathrm{O}}$ & $u_{i}$ & $y_{j}$ \\
\hline $\begin{array}{l}p \in\left[0, H_{p}-2\right] \\
p=H_{p}-1\end{array}$ & $\begin{array}{c}1 \\
10^{2}\end{array}$ & $\begin{array}{c}0.01 \\
10^{2}\end{array}$ & 0.5 & 1 & $\pm 20 \%$ & $\begin{array}{l} \pm 20 \% \\
\pm 1 \%\end{array}$ \\
\hline
\end{tabular}

subject to

$$
\begin{aligned}
x_{r}(k+p+1 \mid k) & =A_{r d} x_{r}(k+p \mid k)+B_{r d} u(k+p \mid k), \\
y(k+p \mid k) & =C_{r d} x_{r}(k+p \mid k)+D_{r d} u(k+p \mid k), \\
x_{r}(k \mid k) & =\hat{x}_{r}(0 \mid k) \\
u^{\min } & \leq u(k+p \mid k) \leq u^{\max }, \\
y^{\min } & \leq y(k+p \mid k) \leq y^{\max },
\end{aligned}
$$

where $p=0, \ldots, H_{p}-1$ is the time instant within the prediction horizon $H_{p} ; w_{y}$ and $w_{r}$ are the output errors and inputs smoothness penalty weights for the cost function, respectively; $\hat{x}_{r}(k) \in \mathbb{R}^{12}$ is the vector of estimated states; and $u^{\min }, u^{\max }$, $y^{\min }, y^{\max }$ correspond to the lower and upper constraints for the inputs and the outputs, respectively.

Note that solving problem (9), a vector of optimal slew rates,

$$
\Delta \mathcal{U}(k)^{*} \triangleq\left[\Delta u(0 \mid k)^{* T} \ldots \Delta u\left(H_{p}-1 \mid k\right)^{* T}\right]^{T} \in \mathbb{R}^{2 H_{p}}
$$

is obtained. At each time instant $k$, problem (9) is solved for the current state and the control movement applied to the system in the previous time instant, namely $u(k-1)$. Only the first optimal slew rate $\Delta u(0 \mid k)^{*}$ of the optimal sequence $\Delta \mathcal{U}(k)^{*}$ is applied to the process previous transformation into a control movement as

$$
u(k)=u(k-1)+\Delta u(0 \mid k)^{*} .
$$

The remaining optimal slew rates are discarded and the optimization is repeated at time instant $k+1$.

In addition, a full-order state observer is depicted in the block diagram. Since the complete state vector is not available, state estimation from the measurement of the NLsys outputs is required. The solution of the optimization problem will be based on an estimation of the reduced state vector, $\hat{x}_{r}(k)$, instead of the true reduced state vector $x_{r}(k)$. For this purpose, a full-state Luenberger observer is used [14], which is expressed as

$$
\hat{x}_{r}(k+1)=\left(A_{r d}-L C_{r d}\right) \hat{x}_{r}(k)+B_{r d} u(k)+L\left(y(k)-D_{r d} u(k)\right),
$$

where $L$ is the estimator gain matrix. The observer is designed by solving the associated Riccati equation assuring that the estimator poles of $\left(A_{r d}-L C_{r d}\right)$ are faster than those of the controlled plant.

The LMPC controller has been tuned considering the previous analysis of the system's behavior. The weights of the cost function are presented in Table 4. Terminal weights and terminal constraints are added in order to ensure stability [15]. Setting $\mathrm{H}_{p}=37$ time instants (i.e., $11 \mathrm{~s}$ ) ensures that the LMPC

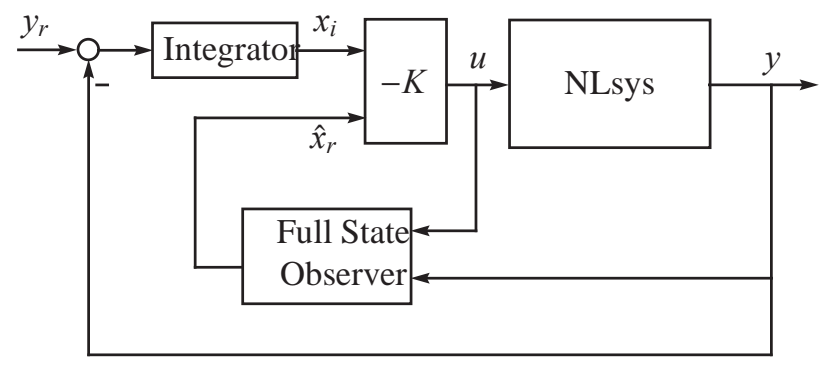

Figure 9: LQRi closed-loop scheme.

controller considers the delay of the NLsys (which is of about $9 \mathrm{~s}$ ) and also assures an adequate horizon for the open-loop prediction. The qpSolve (Active-set) solver from the Tomlab ${ }^{\circledR} 7.5$ allows optimization times inferior to $0.1 \mathrm{~s}$, which correspond to a third of the sampling time considered.

\section{3. $L Q R i$}

Since the LMPC configuration, as defined in Section 5.2, cannot deal with modeling errors or assure error-free steady state, a centralized LQR plus an integrator with output feedback is considered. Figure 9 shows the block diagram for this configuration. The full-state observer corresponds to the one in (10). The discrete-time integrator is based in the forward Euler formula [16],

$$
x_{i}(k+1)=x_{i}(k)+T_{s}\left(y_{r}(k)-y(k)\right),
$$

where $x_{i}(k) \in \mathbb{R}^{2}$ is the vector of integral states of the output errors and $y_{r}(k) \in \mathbb{R}^{2}$ is the vector of output references.

The addition of this integrator increases the number of states of the linear system used for the design of the LQR controller. Therefore, the states of the model LRDsys have to be augmented with $x_{i}(k)$. Thus, the new augmented plant can be expressed as

$$
\left[\begin{array}{c}
x_{r}(k+1) \\
x_{i}(k+1)
\end{array}\right]=\left[\begin{array}{cc}
A_{r d} & 0 \\
-C_{r d} & I
\end{array}\right]\left[\begin{array}{c}
x_{r}(k) \\
x_{i}(k)
\end{array}\right]+\left[\begin{array}{c}
B_{r d} \\
-D_{r d}
\end{array}\right] u(k) .
$$

The LQRi controller is computed using the matrices of the augmented model (11). The discrete LQR controller corresponds to an optimal state feedback matrix, $K$, obtained from the unconstrained minimization of the objective function

$$
J(u)=\sum_{n=1}^{\infty}\left[x_{r a}(n)^{T} Q x_{r a}(n)+u(n)^{T} R u(n)\right],
$$

where, $x_{r a}=\left[x_{r}, x_{i}\right]^{T}$ corresponds to the states of the augmented model (11). The gain matrix $K=\left[K_{i}, K_{p}\right]^{T}$ has also two terms, the first gain matrix $K_{i}$ concerning the $x_{i}$ and the second $K_{p}$ concerning the $x_{r}$. The weights $\mathrm{Q}$ are formed by

$$
Q=\left[\begin{array}{c}
q_{p} \\
q_{i}
\end{array}\right]
$$


where $q_{p}$ are the weights penalizing the states of the plant and $q_{i}$ are the weights penalizing the two states of the output error integrator.

Tuning of the LQRi controller corresponds to the weights ratio $\frac{q_{i}}{R}=10$. Weights $q_{p}=0$ since the states of the controlled plant should not be minimized.

\subsection{Cascade $L M P C+L Q R i$}

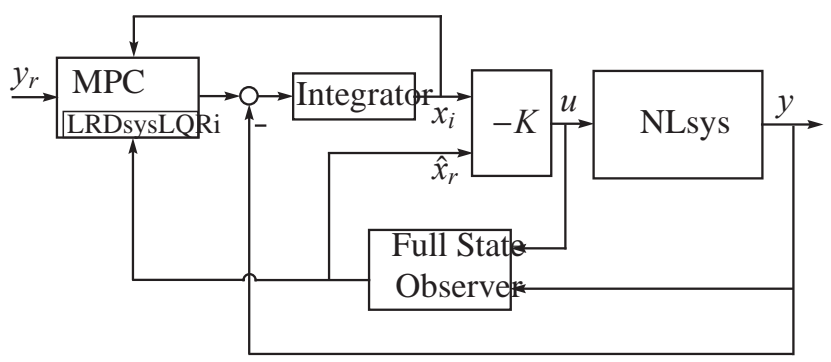

Figure 10: LMPC-LQRi closed-loop scheme.

Since the LQRi configuration assures free steady-state error but does not deal with constraints and the LMPC configuration deals with constraints but does not assure free steady-state error, a combination of both configurations in a cascade scheme is considered in order to overcome the drawbacks of each configuration alone. Thus, two closed loops are considered. The inner loop contains an LQRi as the one presented in Section 5.3, which deals with the modeling errors between the LRDsys and the NLsys models directly. The external loop contains the LMPC, which manages the references given to the LQRi configuration. Figure 10 shows the block diagram for this configuration.

The new model for the external LMPC will be the whole inner loop. Taking the references to the LQRi as the new inputs and the outputs of the NLsys system as the outputs, the statespace representation of the inner closed loop is

$$
\xi(k+1)=\left[\begin{array}{ccc}
A_{r d} & -B_{r d} K_{p} & -B_{r d} K_{i} \\
L C_{r d} & \omega & -B_{r d} K_{i} \\
-T_{s} C_{r d} & T_{s} D_{r d} K_{p} & I+T_{s} D_{r d} K_{i}
\end{array}\right] \xi(k)+\left[\begin{array}{c}
0 \\
0 \\
T_{s}
\end{array}\right] r_{y}(k)
$$

$$
y(k)=\left[\begin{array}{lll}
C_{r d} & -D_{r d} K_{p} & -D_{r d} K_{i}
\end{array}\right] \xi(k),
$$

with the new vector of states

$$
\xi(k)=\left[\begin{array}{c}
\hat{x}_{r}(k) \\
x_{o b s}(k) \\
x_{i}(k)
\end{array}\right]
$$

where $\omega=A_{r d}-L C_{r d}-B_{r d} K_{p}$ and $x_{o b s}(k)=\hat{x}_{r}(k)$ corresponds to the vector of states for the full state observer. The model (12) is denoted as LRDsysLQRi.

The MPC problem (9) is now modified because the model has changed. Thus, the LMPC does not control the input variables to the reformer any more, but the output references given to the LQRi. The cost function (9a) changes to

$$
\min _{\Delta y_{r, c}} \sum_{p=0}^{H_{p}-1}\left[\left\|y(k+p \mid k)-y_{r, c}(k+p \mid k)\right\|_{w_{y}}^{2}+\left\|\Delta y_{r, c}(k+i \mid k)\right\|_{w_{r}}^{2}\right],
$$

and the constraints (9e) are expressed now as

$$
y_{r, c}^{\min } \leq y_{r, c}(k+i \mid k) \leq y_{r, c}^{\max },
$$

where $y_{r, c}^{\min }, y_{r, c}^{\max }$ correspond to the lower and upper constraints for the output references and the weights $w_{r}$ now penalize variations in the references. The new optimization vector for the LMPC problem contains variations in the references given to the LQRi configuration, which change within the prediction horizon.

Tuning parameters for the LQRi inner loop are inherited from Section 5.3. The tuning parameters for the LMPC output loop are $w_{y, H_{2}}=1$ and $w_{y, C O}=w_{r, H_{2}}=w_{r, C O}=0.01$.

\section{Comparison of the Closed-loop Configurations}

The performance of the closed-loop configurations presented in Section 5 has been compared in two different scenarios: first, output tracking and second, additive load disturbances rejection.

Simulations have been carried out using Simulink 7.6 and the TOMLAB ${ }^{\circledR} 7.6$ optimization package for Matlab ${ }^{\circledR}$ R2010b (64 bits). Two solvers have been used, namely, the variable-step solver ode45 Dormand-Prince for the NLsys model in Simulink and qpsolve (AS method) as a quadratic programming solver. Numerical linearization of the NLsys model has been done using the Control System Toolbox ${ }^{\mathrm{TM}}$. The computer used to run the simulations is a PC Intel ${ }^{\circledR}$ Core $^{\mathrm{TM}} 2$ Duo CPU E8600 running both cores at $3.33 \mathrm{GHz}$ with $8.0 \mathrm{~GB}$ of RAM.

\subsection{Output Tracking}

Simulation results are presented in Figure 11. This scenario considers simulations for a $+10 \%$ step change in $y_{r, H_{2}}$ while $y_{r, C O}$ is kept at its nominal value. Constraints are kept at $\pm 20 \%$ as specified in Table 2. KPI values are shown in Table 5. The lowest KPI, meaning the lowest output error or the smoothest control inputs, are highlighted. Analyzing the curves and the KPI, it should be noted that

- Only LQRi and PID configurations ensure error-free steady-state response because of their integral action. However, the output steady-state errors for the LMPC and cascade LMPC-LQRi are less than $1 \%$ and can be considered negligible.

- The PID configuration presents the highest oscillations. It is the slowest response and it does not fulfill any constraints. However, it shows the smoothest control inputs.

- The LMPC configuration shows the best output tracking performance in both $y_{\mathrm{H}_{2}}$ and $y_{\mathrm{CO}}$ with negligible steadystate error (less than $1 \%$ ) and fulfilling all the constraints. 

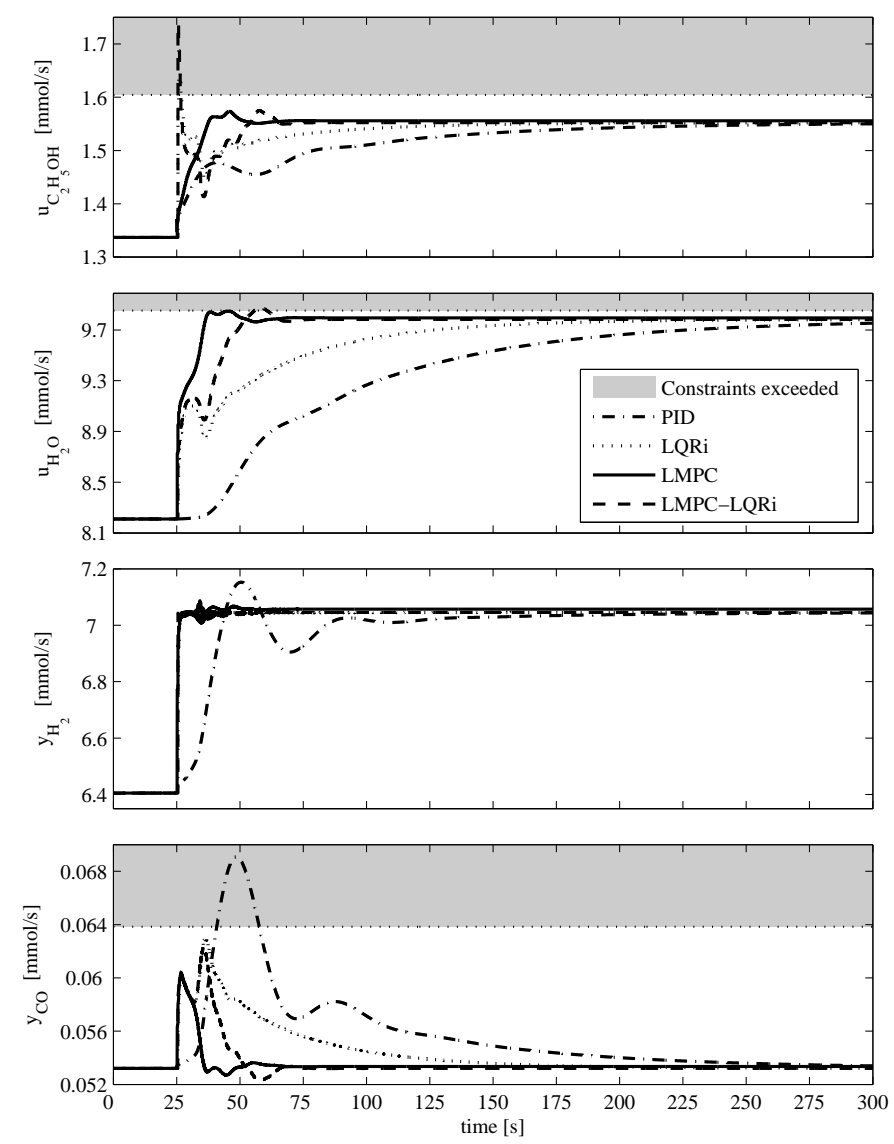

Figure 11: Output tracking performance of all the control configurations. From top to bottom, first and second plots show ethanol and water control inputs while the third and fourth plots show hydrogen and carbon monoxide outputs.

- LQRi and LMPC-LQRi configurations show a better performance than the PID configuration, being the cascade configuration faster, especially bringing $y_{C O}$ back to its nominal value. Nonetheless, both exceed the input constraints in the $u_{\mathrm{C}_{2} \mathrm{H}_{5} \mathrm{OH}}$ and show aggressive control inputs.

In addition, both LMPC and cascade LMPC-LQRi configurations can narrow the upper constraint $y_{C O}^{\max }$ down to $+7.5 \%$ instead of the $+20 \%$ considered in the simulation. Narrowing the upper constraint reduces the $y_{C O}$ overshoot at the expense of losing performance in the tracking of the $y_{\mathrm{H}_{2}}$. The lower constraint $y_{C O}^{\min }$ must be kept at $-20 \%$ in order to avoid infeasibility of the optimization problem.

\subsection{Additive Load Disturbances Rejection}

Simulation results are presented in Figure 12. This scenario considers additive load disturbances at $+10 \%$ step change in both $u_{\mathrm{C}_{2} \mathrm{H}_{5} \mathrm{OH}}$ and $u_{\mathrm{H}_{2} \mathrm{O}}$ with respect to its nominal value, thus the control signals received by the NLsys would be $u+\Delta u$. Constraints are kept at $\pm 20 \%$ as specified in Table 2. KPI values are shown in Table 6. The lowest KPI, meaning the lowest output error or the smoothest control inputs, are highlighted. Analyzing the curves and the KPI, it can be noted that
Table 5: Performance KPI for all the control configurations at the output tracking scenario.

\begin{tabular}{lrrlc}
\hline \multirow{2}{*}{ Controller } & \multicolumn{4}{c}{ KPI $\left[\cdot 10^{-3}\right]$} \\
\cline { 2 - 5 } & \multicolumn{1}{c}{$\mathrm{H}_{2}$} & $\mathrm{CO}$ & $\mathrm{C}_{2} \mathrm{H}_{5} \mathrm{OH}$ & $\mathrm{H}_{2} \mathrm{O}$ \\
\hline PID & 19.2695 & 97.4540 & $\mathbf{0 . 1 0 3 6}$ & $\mathbf{0 . 0 0 5 4}$ \\
LQRi & 3.1648 & 42.3001 & 5.0490 & 1.2891 \\
LMPC & $\mathbf{2 . 1 9 5 3}$ & $\mathbf{1 7 . 4 4 3 7}$ & 0.8919 & 1.9095 \\
LMPC-LQRi & 2.8800 & 29.0933 & 8.4317 & 1.8428 \\
\hline
\end{tabular}

Table 6: Performance KPI for all the control configurations at the load disturbance rejection scenario

\begin{tabular}{lrrrc}
\hline \multirow{2}{*}{ Controller } & \multicolumn{4}{c}{ KPI $\left[\cdot 10^{-3}\right]$} \\
\cline { 2 - 5 } & \multicolumn{1}{c}{$\mathrm{H}_{2}$} & \multicolumn{1}{c}{$\mathrm{CO}$} & $\mathrm{C}_{2} \mathrm{H}_{5} \mathrm{OH}$ & $\mathrm{H}_{2} \mathrm{O}$ \\
\hline PID & 127.9991 & 471.4544 & $\mathbf{0 . 0 9 9 5}$ & $\mathbf{0 . 0 2 0 0}$ \\
LQRi & $\mathbf{2 . 1 8 8 6}$ & 48.2085 & 8.6979 & 1.8433 \\
LMPC & 10.9194 & 147.4150 & 0.8201 & 1.2705 \\
LMPC-LQRi & 7.9488 & $\mathbf{3 6 . 0 6 3 7}$ & 16.2757 & 3.4082 \\
\hline
\end{tabular}

- The PID configuration presents the highest oscillations and does not fulfill any constraints. However, it shows the smoothest control inputs and ensures error-free steady state responses.

- The LMPC configuration does not consider feed-forward compensation of the load disturbances and thus performance gets affected showing high steady-state errors. Although the $y_{C O}$ exceeds the upper constraint when the $\Delta u_{\mathrm{C}_{2} \mathrm{H}_{5} \mathrm{OH}}$ is applied, the LMPC controller internally fulfills all the constraints and this graphical divergence is due to modeling errors between the LRDsys and NLsys models (up to $16 \%$ on the constraints).

- The LQRi configuration ensures error-free steady-state responses and shows the lowest output error in $y_{H_{2}}$. It presents an aggressive $u_{\mathrm{C}_{2} \mathrm{H}_{\mathrm{O}} \mathrm{H}}$ exceeding the constraints when the disturbance $\Delta u_{H_{2} O}$ is active.

- The cascade LMPC-LQRi configuration presents the lowest output error in $y_{C O}$ at expenses of presenting the most aggressive control inputs. Although this configuration can not ensure error-free steady-state response, it can be considered negligible (less than $1 \%$ ).

\section{Conclusions and Further Work}

Tables 7 and 8 summarize the performance of each configuration based on the output error and input smoothness KPI obtained during the simulations in the previous section. Table 7 shows characteristics that can be either assured or not, while 

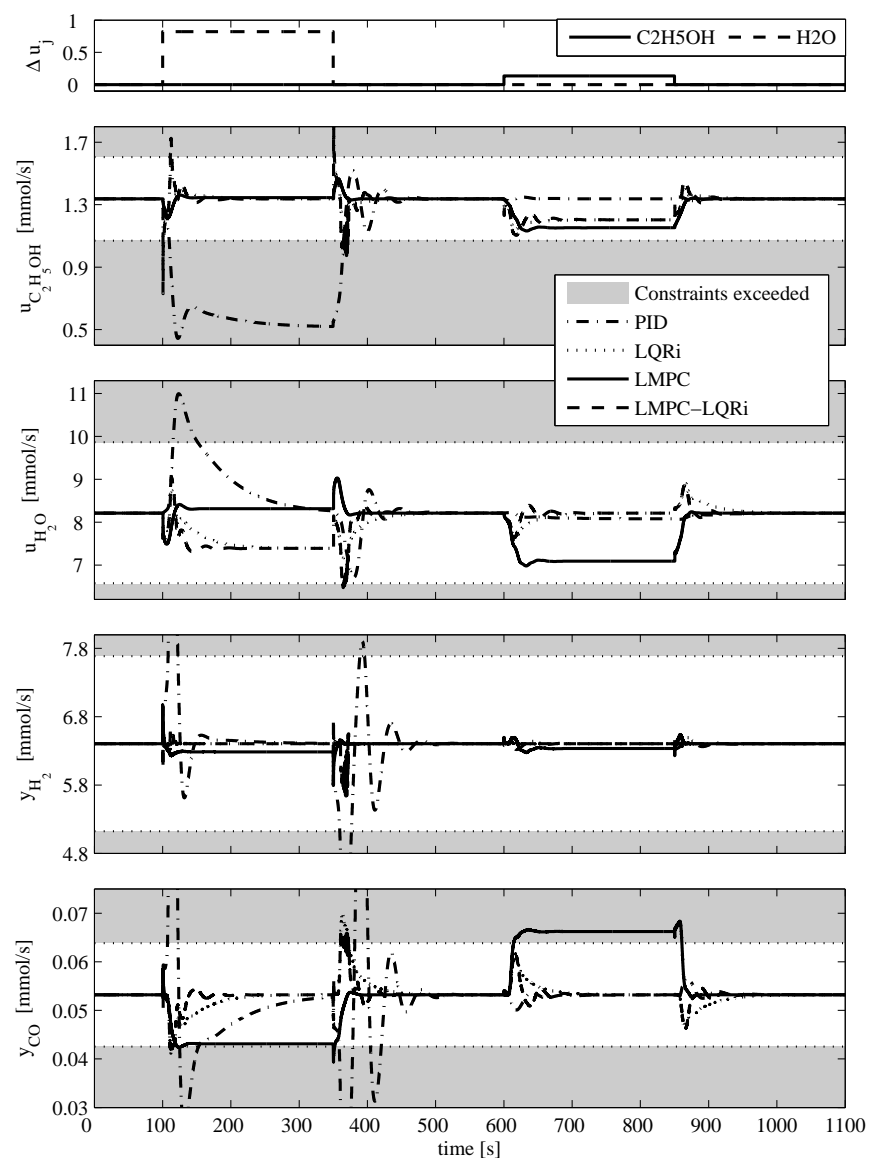

Figure 12: Load disturbance rejection performance of all the control configurations. From top to bottom, first plot shows the two input disturbances profile, second and third plots show ethanol and water control inputs while the fourth and fifth plots show hydrogen and carbon monoxide outputs.

Table 8 shows a ranking of how the configurations fit different features. Thus, the characteristics of the four configurations are the following:

- The decentralized PID configuration assures output errorfree steady-state and ranks the highest input smoothness. However, this configuration presents high oscillations and the worst tracking and load disturbance rejection performances. None of the constraints can be considered in this configuration and are therefore exceeded.

- The LQRi configuration assures output error-free steadystate, presents no oscillations in $y_{H_{2}}$ and shows the load best disturbance rejection performance. However, this configuration ranks both the output tracking and input smoothness performances at third position. None of the constraints are considered and are therefore exceeded.

- The LMPC configuration presents no oscillations in $y_{H_{2}}$, fulfills all the constraints and allows narrowing the $y_{C O}$ upper constraint. Furthermore, it presents the best output tracking with negligible steady-state error (less than 1\%) and good inputs smoothness. However, this configuration

Table 8: Comparison of the output tracking, inputs smoothness and load disturbance rejection of each control configuration. Ranking -1 : best performance, ..., 4: worst performance.

\begin{tabular}{cccc}
\hline Ranking & $\begin{array}{c}\text { Outputs } \\
\text { tracking }\end{array}$ & $\begin{array}{c}\text { Load disturbance } \\
\text { rejection }\end{array}$ & $\begin{array}{c}\text { Inputs } \\
\text { smoothness }\end{array}$ \\
\hline 1 & LMPC & LQRi & PID \\
2 & LMPC-LQRi & LMPC-LQRi & LMPC \\
3 & LQRi & LMPC & LQRi \\
4 & PID & PID & LMPC-LQRi \\
\hline
\end{tabular}

shows incapability in load disturbance rejection showing high steady-state errors while the disturbances are active.

- The LMPC-LQRi configuration combines the performance of LQRi and LMPC configurations. Therefore, both its tracking and load disturbance rejection performances are ranked in second place. Furthermore, it presents no oscillations in $y_{H_{2}}$, fulfills the output constraints and allows narrowing the $y_{C O}$ upper constraint. Although error-free steady state can not be assured, steadystate error is negligible (less than 1\%). However, the control inputs are the most aggressive and input constraints are not fulfilled since the LMPC does not deal with the control inputs directly.

- The cascade LMPC-LQRi configuration is globally the best positioned. Even so, depending on the priority of the criteria chosen for the control problem other configurations might be more suitable.

Further work would consider a ESR with non isothermal conditions, and therefore, energy balances would also be considered in the mathematical modeling. Another goal would regard with multi-rate configurations in order to be able to control both fast and slow dynamics, i.e., molar flow rates and temperatures simultaneously. Important aspects related to the efficiency of the ERS as a part of a hydrogen-based system are open lines for future research. Moreover, experimental validation of the NLsys model is also another point to keep in mind in further steps.

\section{Acknowledgements}

This work has been partially supported by Spanish research projects DPI2010-15274 and DPI2011-25649 of the Science and Innovation Ministry.

\section{Notation}

C

$F$

$Q$

$r$ concentration, $\mathrm{mmol} \mathrm{m}^{-3}$ molar flow rate, $\mathrm{mmol} \mathrm{s}^{-1}$ volumetric flow rate, $\mathrm{m}^{3} \mathrm{~s}^{-1}$ reaction rate, $\mathrm{mol} \mathrm{m}^{-3} \mathrm{~s}^{-1}$ 
Table 7: Comparison of the error, overshoot and constraints fulfillment of each closed-loop configuration. $\sqrt{ }$ : assured, "blank": not assured.

\begin{tabular}{lccccc}
\hline \multirow{2}{*}{ Scheme } & Error-free & No oscilla- & \multicolumn{2}{c}{ Constraints } & Constraints \\
& steady state & tions in $\mathrm{H}_{2}$ & Inputs & Outputs & narrowing \\
\hline PID & $\sqrt{ }$ & & & & \\
LQRi & $\sqrt{ }$ & $\sqrt{ }$ & & & \\
LMPC & & $\sqrt{ }$ & $\sqrt{ }$ & $\sqrt{ }$ & $\sqrt{ }$ \\
LMPC-LQRi & & $\sqrt{ }$ & & $\sqrt{ }$ & $\sqrt{ }$ \\
\hline
\end{tabular}

$\eta^{H_{2}}$

$\mathrm{X}_{\mathrm{C}_{2} \mathrm{H}_{5} \mathrm{OH}}$

$\mathrm{X}_{\mathrm{C}_{2} \mathrm{H}_{4} \mathrm{O}}$

$\gamma_{\mathrm{CO}}$

$A_{r d}, B_{r d}, C_{r d}, D_{r d}$

$\mathrm{CMO}$

K

$K_{i}$

$K_{p}$

KPI

$L$

LRDsys

MI

NLsys

$T_{S}$

$u$

$x_{r}(k)$

$x_{i}(k)$

$y$

\section{1, 2, 3 (superscript) \\ $c$ (subscript) \\ $g$ (subscript) \\ $i$ (subscript)}

in (subscript)

$j$ (subscript)

$L$ (subscript) linear velocity of the gases, $\mathrm{m} \mathrm{s}^{-1}$ axial coordinate of the reactor, $m$ reagents-products molar relation, adimensional

$\mathrm{H}_{2}$ yield, \%

$\mathrm{C}_{2} \mathrm{H}_{5} \mathrm{OH}$ conversion, \%

$\mathrm{C}_{2} \mathrm{H}_{4} \mathrm{O}$ conversion, \%

$\mathrm{CO}$ molar fraction, $\%$

state space matrices for the LRDsys model

measured controlled outputs

LQR optimal gain state feedback matrix, $K=\left[K_{i}, K_{p}\right]^{T}$

submatrix of $K$ related to the integrator states

submatrix of $K$ related to the plant states

key performance indicator

full-state observer gain matrix

linear control-oriented model

manipulated input

non-linear simulation model

sampling time, $\mathrm{s}$

control inputs

vector of reduced states for the

LRDsys model

vector of integrated output states

outputs of the system

stages 1,2 and 3 respectively

outputs, $c \in\left\{\mathrm{H}_{2}, \mathrm{CO}\right\}$

inputs, $g \in\left\{\mathrm{C}_{2} \mathrm{H}_{5} \mathrm{OH}, \mathrm{H}_{2} \mathrm{O}\right\}$

reaction number, $i=1, \ldots, 3$

(reactions (1) to (3))

refers to the inlet of the reactor, $z=0$

component number, $j=1, \ldots, 6$

$\left(\mathrm{C}_{2} \mathrm{H}_{5} \mathrm{OH}, \ldots, \mathrm{CO}_{2}\right)$

refers to the outlet of the reactor, $z=L$
[2] A. Haryanto, S. Fernando, N. Murali, S. Adhikari, Current status of hydrogen production techniques by steam reforming of ethanol: a review, Energy \& Fuels 19 (2005) 2098-2106.

[3] J. Llorca, N. Homs, J. Sales, P. R. de la Piscina, Efficient production of hydrogen over supported cobalt catalysts from ethanol steam reforming, Journal of Catalysis 209 (2002) 306-317.

[4] V. M. García, E. López, M. Serra, J. Llorca, Dynamic modeling of a threestage low temperature ethanol reformer for fuel cell application, Journal of Power Sources 192 (2009) 208-215.

[5] W. F, Podolski, Y. G. Kim, Modeling the water-gas shift reaction, Ind. Eng. Chem., Process Des. Develop. 13 (4).

[6] L. E. Arteaga, L. M. Peralta, Y. Casas, D. Castro, Optimal design, modeling and simulation of an ethanol steam reforming reactor, International Journal of Chemical Reactor Engineering 7 (2009) article A59.

[7] W. L. Luyben, Process modeling, simulation and control for chemical engineers, 2nd Edition, Chemical engineering, MacGraw-Hill New York, 1989.

[8] V. M. García, E. López, M. Serra, J. Llorca, J. Riera, Dynamic modeling and controllability analysis of an ethanol reformer for fuel cell application, International Journal of Hydrogen Energy 35 (2010) 9768-9775.

[9] S. Biset, L. N. Deglioumini, M. Basualdo, V. M. García, M. Serra, Analysis of the control structures for an integrated ethanol processor for proton exchange membrane fuel cell systems, Journal of Power Sources.

[10] J. M. Maciejowski, Predictive control with constraints, Prentice Hall, 2001.

[11] S. Skogestad, I. Postlethwaite, Multivariable feedback control. Analysis and design, Wiley, 1996; 2005.

[12] J. Llorca, N. Homs, J. Sales, J. G. Fierro, P. R. de la Piscina, Effect of sodium addition on the performance of co-zno-based catalysts for hydrogen production from bioethanol, Journal of Catalysis 222 (2004) 470480 .

[13] H. S. Fogler, Elements of chemical reaction engineering, 4th Edition, Pearson Education, 2006.

[14] K. Ogata, Discrete-Time Control Systems, 2nd Edition, Prentice Hall, Inc, 1995.

[15] D. Mayne, J. Rawlings, C. Rao, P. Scokaert, Constrained model predictive control: Stability and optimality, Automatica 36 (2000) 789-814.

[16] The MathWorks, Inc, Control System Toolbox, User's Guide (2010).

\section{Appendix A. Kinetic Equations}

The reaction rate expresses how fast the reaction happens. Because this term depends on the chemical reaction that takes place, it is defined for each of the three stages of the ESR independently. Refer to Appendix B to know more about the values of the different parameters in each stage. The different parameters were experimentally obtained in [4].

\section{Appendix A.1. Stage 1-Ethanol Dehydrogenation}

In this stage the reaction (1), follows a first order equation, so the reaction rate can be expressed, using the Arrhenius law,
[1] J. Holladay, J. Hu, D. King, Y. Wang, An overview of hydrogen production technologies, Catalysis Today 139 (2010) 244-260. 
as

$$
r_{1}=k_{\infty}^{1} e^{\frac{E a}{R T}} C_{C_{2} H_{5} O H}
$$

where $k_{\infty}$ is the pre-exponential factor in $\mathrm{s}^{-1}, R$ is the universal gas constant in $\mathrm{J} \mathrm{K}^{-1} \mathrm{~mol}^{-1}, T$ is the temperature in $\mathrm{K}$ and $E_{a}$ is the activation energy in $\mathrm{J} \mathrm{mol}^{-1}$.

\section{Appendix A.2. Stage 2 - Acetaldehyde Reforming}

In this stage three reactions take place, two in parallel, reactions (2a) and (2b), and one in series, reaction (2c). Both parallel reactions present a first order rate reaction, while the series reaction depends on the partial pressures of different components as it can be seen in

$$
\begin{aligned}
& r_{1}=k_{\infty, 1}^{2} e^{\frac{E a_{1}^{2}}{R T}} C_{C_{2} \mathrm{H}_{4} O}, \\
& r_{2}=k_{\infty, 2}^{2} e^{\frac{E a_{2}^{2}}{R T}} C_{C_{2} H_{4} O}, \\
& r_{3}=k_{\infty, 3}^{2} e^{\frac{E a_{3}^{2}}{R T}} C_{C_{2} \mathrm{H}_{4} O} p_{C O} p_{H_{2} O}\left(1-\frac{1}{K_{e q 3}} \frac{p_{C O_{2}} p_{H_{2}}}{p_{C O} p_{H_{2} O}}\right),
\end{aligned}
$$

where $p_{\mathrm{CO}}, p_{\mathrm{H}_{2} \mathrm{O}}, p_{\mathrm{CO}_{2}}, p_{\mathrm{H}_{2}}$ correspond to the partial pressures for the different chemical components in $\mathrm{Pa}$ and $K_{e q, 3}$ is a constant in $\mathrm{s}^{-1}$.

\section{Appendix A.3. Stage 3 - Water Gas Shift}

Equation (3) is the only reversible reaction in the whole unit. This reaction follows a Langmuir-Hinshelwood model to describe its kinetics

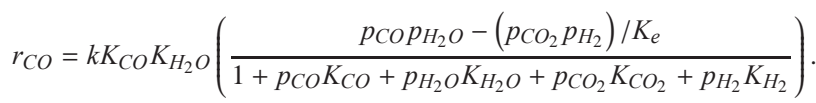

where $k$ is the rate constant in $\mathrm{mol} \mathrm{m}^{-3} \mathrm{~s}^{-1}, K_{e}$ is the adimensional equilibrium constant for homogeneous reaction and $K_{C O}$, $K_{\mathrm{H}_{2} \mathrm{O}}, K_{e}, K_{\mathrm{CO}_{2}}, K_{\mathrm{H}_{2}}$ are the adsorption equilibrium constants of each component in $\mathrm{Pa}^{-1}$.

\section{Appendix B. Reformer Parameters}

\section{STAGE 1:}

$\overline{\mathrm{V}}^{1}=310^{-3}$

$\varepsilon^{1}=1 / 7.14$

$\mathrm{Ea}^{1}=67.32$

$\mathrm{k}_{\infty}^{1}=1.5510^{5}$

\section{STAGE 2:}

$\mathrm{V}^{2}=3.110^{-3}$

$\varepsilon^{2}=6 / 17.18$

$\mathrm{Ea}_{1}^{2}=98.4$

$\mathrm{Ea}_{2}^{2}=98.4$

$\mathrm{Ea}_{3}^{2}=122$

$\mathrm{k}_{\infty, 1}^{2}=12.4910^{6}$

$\mathrm{k}_{\infty, 2}^{2,1}=12.4910^{6}$

$\mathrm{k}_{\infty, 3}^{2}=210^{5}$

volume, $\mathrm{m}^{3}$ reagents-products molar relation, adim. activation energy, $\mathrm{J} \mathrm{mmol}^{-1}$ preexponential const., $\mathrm{s}^{-1}$

\section{STAGE 3:}

$\varepsilon^{3}=0$

$\mathrm{k}=64910^{8}$

$\mathrm{K}_{e}=62.66$

$\mathrm{K}_{C O}=41.62$

$\mathrm{K}_{\mathrm{H}_{2} \mathrm{O}}=3.75$

$\mathrm{K}_{\mathrm{CO}_{2}}=2.75$

$\mathrm{K}_{\mathrm{H}_{2}}=62.66$ reagents-products molar relation, adim. rate const., $\mathrm{mol} \mathrm{m}^{-3} \mathrm{~s}^{-1}$ equilibrium const. for homogeneous reaction, adim. adsorption equilibrium const.s of $\mathrm{CO}, \mathrm{Pa}^{-1}$ adsorption equilibrium const.s of $\mathrm{H}_{2} \mathrm{O}, \mathrm{Pa}^{-1}$ adsorption equilibrium const.s of $\mathrm{CO}_{2}, \mathrm{~Pa}^{-1}$ adsorption equilibrium const.s of $\mathrm{H}_{2}, \mathrm{~Pa}^{-1}$ 